\title{
DEPOSISI LAPISAN TIPIS ZnO:AI PADA SUBSTRAT ALUMINA UNTUK BAHAN SENSOR GAS
}

\author{
Sayono, Tjipto Sujitno \\ Pusat Teknologi Akselerator dan Proses Bahan - BATAN \\ Toto Trikasjono \\ Sekolah Tinggi Teknologi Nuklir - BATAN
}

\begin{abstract}
ABSTRAK
DEPOSISI LAPISAN TIPIS ZnO:AI PADA SUBSTRAT ALUMINA UNTUK BAHAN SENSOR GAS. Telah dilakukan deposisi lapisan tipis ZnO:Al pada substrat alumina menggunakan teknik DC Sputtering untuk aplikasi sensor gas. Deposisi lapisan tipis ZnO:Al dilakukan dengan parameter proses sputtering tegangan elektroda DC sebesar $2.2 \mathrm{kV}$, arus $10 \mathrm{~mA}$ dan suhu substrat $250^{\circ} \mathrm{C}$, waktu deposisi divariasi 30 - 150 menit dengan interval 30 menit dan tekanan divariasi masing-masing : $1 \times 10^{-2} \mathrm{~atm}, 2 \times 10^{-2} \mathrm{~atm}, 3 \times 10^{-2} \mathrm{~atm}, 4 \times 10^{-2} \mathrm{~atm}$ dan $5 \times 10^{-2} \mathrm{~atm}$. Dari hasil karakterisasi diperoleh nilai resistansi terendah sebesar $64 \mathrm{k} \Omega$ diperoleh pada kondisi waktu deposisi 90 menit dan tekanan operasi $4 \times 10^{-2}$ atm. Hasil pengukuran sensitivitas menunjukkan bahwa sensor gas dari bahan $\mathrm{ZnO}$ :Al mempunyai sensitivitas tertinggi terhadap gas sensor $\mathrm{C}_{2} \mathrm{H}_{5} \mathrm{OH}$ sebesar $24 \%$, untuk gas $\mathrm{NH}_{3}$ sebesar $19,77 \%$ dan untuk gas $\mathrm{SO}_{2}$ sebesar $17,53 \%$ pada 141,54 konsentrasi/volume.
\end{abstract}

Kata kunci : deposisi, sputtering, resistansi, sensor gas

\section{ABSTRACT}

A THIN FILM DEPOSITION OF ZnO:AI THIN FILM ON THE ALUMINA SUBSTRATE FOR GAS SENSOR. The thin layer deposition of ZnO:Al on the alumina substrate by using sputtering method for gas sensor application has been done. Deposition of $\mathrm{ZnO}: \mathrm{Al}$ thin film was carried out with following sputtering parameters i.e. : electrodes voltage of 2.2 $\mathrm{kV}$, current $10 \mathrm{~mA}$ and temperature $250^{\circ} \mathrm{C}$, variation of deposition time from 30 to 150 minutes with 30 minutes interval and variation of vacuum pressure : $1 \times 10^{-2} \mathrm{~atm}, 2 \times 10^{-2} \mathrm{~atm}, 3 \times 10^{-3} \mathrm{~atm}, 4 \times 10^{-2} \mathrm{~atm}$ and $5 \times 10^{-2} \mathrm{~atm}$. From the characterization it was found that the lowest resistance in $64 \mathrm{k} \Omega$ order which is obtained in 90 minutes of deposition time and operation pressure $4 \times 10^{-2} \mathrm{~atm}$. Measurement result show the optimum that sensitivity $24 \%$ for $\mathrm{C}_{2} \mathrm{H}_{5} \mathrm{OH}$ gas, $19.77 \%$ for $\mathrm{NH}_{3}$ gas and $17.53 \%$ for $\mathrm{SO}_{2}$ gas that sensitivity at 141.54 concentration/volume.

Key word: Deposition, Sputtering, resistance, Sensor

\section{PENDAHULUAN}

roses pembangunan di segala bidang selain membawa kemajuan terhadap kehidupan manusia, tetapi juga akan membawa dampak negatif bagi lingkungan hidup. Industrialisasi yang semakin meningkat telah menyebabkan menurunnya kualitas lingkungan hidup, karena berbagai jenis limbah yang ditimbulkannya. Seperti halnya penurunan kualitas udara selain diakibatkan dari asap kendaraan bermotor juga limbah dari industri. Kehadiran berbagai jenis gas tersebut pada tingkat tertentu telah semakin mengkhawatirkan bagi kehidupan makhluk hidup. Melihat fenomena tersebut, maka penelitian tentang bahan sensor gas sangat diperlukan.

Semikonduktor oksida mempunyai rancangan sederhana dan harga yang relatif murah, hal ini menyebabkan bahan tersebut menonjol sebagai pilihan untuk digunakan dalam penyediaan perangkat multisensor ${ }^{(1]}$, Walaupun demikian penggunaan semikonduktor oksida sebagai sensor gas terus mengalami penyempurnaan khususnya sifat sensitivitas, selektivitas dan stabilitas yang merupakan hal penting dalam perangkat sensor gas.

Lapisan tipis oksida logam merupakan satu jenis dari sekian banyak bahan lapisan tipis yang telah dikembangkan menjadi sensor gas semi-konduktor. Keadaan ini dimungkinkan karena struktur dan sifat elektrik lapisan tipis oksida dapat dikontrol dalam proses pembuatannya, sehingga dapat mengubah tingkat sensitivitasnya jika berada dalam lingkugan gas.

Banyak teknik yang digunakan untuk membuat lapisan tipis (thin film), diantaranya adalah dengan metode sputtering. Salah satu keunggulan dari metode sputtering adalah dapat menyediakan bahan lapisan tipis yang seragam, padat (dense), memenuhi stoikiometri, sifat elektrik lapisan tipis oksida dapat dikontrol dalam proses 
pembuatannya dan apabila proses sputtering telah dimatikan, maka seluruh proses deposisi akan segera berhenti ${ }^{[2]}$.

Pada proses sputtering, besaran yang cukup penting adalah sputtering yield yang didefinisikan sebagai jumlah atom yang dipancarkan dari target per ion datang ${ }^{[3]}$. Sputtering yield dipengaruhi oleh beberapa faktor diantaranya massa ion target, massa ion penumbuk, energi ion datang dan suhu target. Sedangkan sifat dan struktur hasil dari lapisan tipis dengan teknik DC sputtering dipengaruhi oleh parameter-parameter proses, diantaranya : tekanan gas sputter, suhu subsrat, dan laju deposisi.

Pada penelitian ini telah dilakukan deposisi dan karakterisasi lapisan tipis $\mathrm{ZnO}: \mathrm{Al}$ untuk bahan sensor gas dengan teknik $D C$ sputtering. Untuk mengetahui keberhasilan pembuatan lapisan tipis ZnO:Al sebagai bahan sensor gas, maka dilakukan pengukuran resistansi, penentuan suhu operasi sensor dan sensitivitas terhadap gas uji : $\mathrm{C}_{2} \mathrm{H}_{5} \mathrm{OH}, \mathrm{NH}_{3}$ dan $\mathrm{SO}_{2}$.

Adapun tujuan dari penelitian ini adalah untuk mengetahui pengaruh waktu deposisi dan tekanan operasi sputtering terhadap sensitivitas sensor gas.

Hasil dari penelitian ini diharapkan dapat memberikan informasi mengenai pengaruh waktu deposisi dan tekanan operasi terhadap kenaikan sensitivitas serapan gas lapisan tipis ZnO:Al. Sehingga dapat dijadikan acuan bagi penelitian selanjutnya dan dapat dimanfaatkan oleh dunia industri untuk memenuhi kebutuhan sensor gas pada khususnya dan bidang mikro elektronika pada umumnya di masa yang akan datang.

\section{DASAR TEORI}

Sistem DC sputtering terdiri dari dua elektroda yaitu anoda dan katoda. Pada anoda ditempatkan substrat (bahan yang akan dilapisi) yang dilengkapi dengan pemanas untuk membuka pori-pori substrat, sehingga bahan yang dideposisi di atas permukaan substrat dapat melekat lebih kuat dan tidak mudah mengelupas. Pada katoda dipasang bahan target dan dilengkapi dengan pendingin (water cooling system) yang berfungsi menghindarkan bahan target agar tidak mengalami perubahan bentuk/meleleh akibat suhu yang terlalu tinggi.

Untuk membersihkan molekul-molekul dalam tabung reaktor plasma agar diperoleh tekanan yang rendah, maka dilakukan penghampaan dengan pompa rotari dan difusi. Pompa rotari untuk menghampakan hingga tekanan $10^{-2}$ Torr kemudian dilanjutkan dengan pompa difusi hingga tekanan mencapai $10^{-5}$ Torr.

\section{Parameter Proses Sputtering}

Waktu deposisi dan tekanan merupakan parameter yang memegang peran penting dalam proses sputtering. Semakin lama waktu yang diperlukan untuk proses sputtering, maka akan semakin besar pula jumlah bahan target yang terpercik ke permukaan substrat yang akan dilapisi. Sedang bila tekanan semakin besar maka ion-ion penumbuk target akan semakin banyak sehingga percikan atom target yang dihasilkan semakin banyak. Namun demikian baik waktu deposisi maupun tekanan sputtering mempunyai batas tertentu atau ada kondisi tertentu yang merupakan kondisi optimum. berikut $^{[3]}$ :

Banyaknya bahan yang terpercik per satuan luas katoda secara matematis dapat diformulasikan sebagai

$$
W_{0}=\frac{j_{+} S t A}{e N_{A}}
$$

dengan: $W_{0}=$ Banyaknya atom yang terpercik per satuan luas katoda $\left(\right.$ atom $\left./ \mathrm{cm}^{2}\right), j_{+}=$rapat arus berkas ion $(\mathrm{mA} /$ $\left.\mathrm{cm}^{2}\right), S=$ sputter yield (atom/ion), $t=$ waktu sputtering (detik), $A=$ berat atom (amu), $e=$ muatan elektron $(1,6 \times$ $10^{23}$ atom $/ \mathrm{mol}$ ) dan $N_{A}=$ bilangan Avogadro.

Jumlah bahan yang terpercik menempel pada substrat secara matematis diformulasikan sebagai berikut ${ }^{[3]}$.

$$
W \cong k \frac{W_{0}}{p d}
$$


dengan $k=$ konstanta $=r_{d} r_{a}$ dengan $r_{c}$ dan $r_{a}$ masing-masing adalah jari-jari katoda dan anoda (bernilai 1 untuk sistem planar), $W_{0}=$ banyak partikel yang terpercik dari satuan luas katode, $p=$ tekanan gas lucutan (Torr) dan $d=$ jarak antara elektroda $(\mathrm{cm})$

Laju pemindahan atom permukaan yang diakibatkan oleh penembakan ion disebut sebagai hasil sputter (S), yang secara matematis diformulasikan ${ }^{[3]}$ :

$$
S=\frac{\text { Atom yang dipindahkan }}{\text { lon yang datang }}
$$

\section{Energi Sputtering}

Pendeposisian lapisan tipis pada substrat merupakan bentuk transfer energi atau transfer momentum. Energi kinetik ion-ion positif yang tertarik ke bahan target (katoda) berasal dari medan listrik akibat beda potensial yang diberikan. Agar proses deposisi dapat terjadi, maka besar energi kinetik ion-ion positif harus lebih besar daripada energi ikat bahan target. Besarnya energi yang dipindahkan saat proses tumbukan secara matematis dapat dirumuskan ${ }^{[3]}$ :

$$
E_{1}=\frac{4 M_{1} M_{2}}{\left(M_{1}+M_{2}\right)^{2}} E_{2}
$$

dengan $E_{1}=$ energi kinetik partikel penumbuk, $M_{1}=$ massa partikel penumbuk, $M_{2}=$ massa partikel target, $E_{2}=$ energi yang ditransfer partikel bermassa $M_{1}$ ke atom $M_{2}$.

Adanya tumbukan dari ion-ion positif sebesar $E_{1}$ menyebabkan atom-atom bahan target tercungkil dan akibat adanya transfer momentum atom tersebut terpercik ke segala arah utamanya ke arah substrat. Karena proses tersebut berlangsung kontinyu selama waktu tertentu, proses pelapisan akan berlangsung terus sehingga terjadi interdifusi antar atom hingga terbentuk suatu lapisan tipis.

\section{Mekanisme Serapan Gas}

Bahan semikonduktor sensor gas tersusun atas sensor kimia listrik yang mampu merespon perubahan lingkungan kimia dengan menghasilkan sinyal listrik. Cara kerja sensor gas semikonduktor berpedoman pada fakta bahwa karakteristik listrik dari bahan bergantung pada jumlah molekul teradsorbsi.

Terdapat dua jenis serapan yang terjadi pada semikonduktor oksida logam, yaitu serapan fisika dan serapan kimia. Serapan fisika pada proses adsorbsi adalah serapan gas akibat adanya gaya Van der Walls yaitu gaya yang terjadi akibat medan listrik. Sedangkan serapan kimia pada adsorbsi terkait dengan pembentukan ikatan kimia antara molekul teradsorbsi dengan permukaan semi-konduktor oksida logam.

Serapan Gas

Pada kondisi udara normal, permukaan bahan semikonduktor terlapisi oleh suatu lapisan yang diakibatkan oleh terserapnya oksigen. Proses ini meliputi penyerapan fisika, yang kemudian diikuti penyerapan kimia dengan menangkap elektron dari daerah dekat permukaan semikonduktor. Proses terserapnya gas oksigen di atas permukaan semi-konduktor yang secara matematis dapat di tulis ${ }^{[4]}$ :

$$
\begin{aligned}
1 / 2 \mathrm{O}_{2(\mathrm{~g})} & \Leftrightarrow \mathrm{O}_{(\mathrm{ads})} \\
\mathrm{O}_{(\mathrm{ads})} & +2 \mathrm{e}^{-} \Leftarrow \Rightarrow \mathrm{O}_{(\mathrm{ads})}
\end{aligned}
$$

\section{Sensitivitas}

Sensitivitas merupakan kemampuan sensor untuk mendeteksi kehadiran sejumlah gas dalam jumlah yang kecil, yang secara matematis dapat diformulasikan ${ }^{[5]}$ :

$$
S=\frac{\Delta R}{R_{n}} \times 100 \%=\frac{\left|R_{n}-R_{g}\right|}{R_{n}} \times 100 \%
$$


dengan $S=$ sensitivitas $(\%), R_{n}=$ resistansi pada udara normal $(\Omega), R_{g}=$ resistansi ketika diberi gas $(\Omega)$, dengan $R_{n}$ dan $R_{g}$ terukur pada kondisi isotermal.

\section{TATA KERJA PENELITIAN}

\section{Pembuatan Target dan Penyiapan substrat}

Pembuatan target $\mathrm{ZnO}$ :Al dilakukan dengan mencampur 30 gram bubuk $\mathrm{ZnO}$ dan 0,45 gram bubuk $\mathrm{Al}$ dengan alkohol sehingga diperoleh bubuk adonan yang relatif lembab untuk dapat dibuat dalam bentuk pelet, kemudian adonan tersebut dipres dengan tekanan $150 \mathrm{kN}$ selama kurang lebih 5 - 10 menit sehingga diperoleh pelet $\mathrm{ZnO}: \mathrm{Al}$ dengan diameter $60 \mathrm{~mm}$ serta ketebalan $3 \mathrm{~mm}$. Selanjutnya agar diperoleh pelet yang lebih keras dan tidak mudah pecah, maka target tersebut dianil pada suhu $750{ }^{\circ} \mathrm{C}$ selama 1 jam.

Substrat yang akan dideposisi terbuat dari alumina $\left(\mathrm{Al}_{2} \mathrm{O}_{3}\right)$ dengan tebal $1,5 \mathrm{~mm}$ dan dipotong dengan ukuran $15 \times 57 \mathrm{~mm}$. Kemudian untuk membersihkan kotoran/lemak yang menempel di atas permukaan substrat, maka dilakukan pencucian dengan detergen dan alkohol menggunakan ultrasonic cleaner masing-masing selama 20 menit. Selanjutnya substrat dikeringkan menggunakan pemanas pada suhu $100{ }^{\circ} \mathrm{C}$ selama 1 jam.

\section{Pembuatan lapisan tipis ZnO:Al}

Untuk pembuatan lapisan tipis $\mathrm{ZnO}: \mathrm{Al}$ di atas permukaan substrat alumina dilakukan melalui 2 tahap yakni pertama proses pendeposisian lapisan tipis Au sebagai elekroda dan sistem pemanas sensor dan tahap kedua pembuatan lapisan tipis ZnO:Al sebagai bahan aktif sensor. Pendeposisian dilakukan dengan menvariasi parameter proses yaitu waktu dan tekanan sputtering. Skema alat DC Sputtering disajikan pada Gambar 1.

Proses pendeposisian lapisan tipis ZnO:Al adalah sebagai berikut: memasang target $\mathrm{ZnO}: \mathrm{Al}$ pada katoda dan substrat alumina yang telah dibersihkan pada anoda. Kemudian tabung reaktor plasma dihampakan dengan pompa rotari hingga mencapai tekanan $10^{-2} \mathrm{~atm}$, kemudian pompa difusi dihidupkan untuk menghampakan tabung sputtering agar dicapai tingkat kevakuman $10^{-5} \mathrm{~atm}$, selanjutnya gas argon dimasukkan ke dalam tabung sputtering hingga tekanan kerja operasi tercapai $\left(10^{-2} \mathrm{~atm}\right)$, selanjutnya tegangan tinggi dc dihidupkan hingga mencapai tegangan $2,2 \mathrm{kV}$ dan arus $20 \mathrm{~mA}$. Langkah pendeposisian diulangi untuk setiap waktu deposisi dan tekanan yaitu pada variasi tekanan : $1 \times 10^{-2} \mathrm{~atm}, 2 \times 10^{-2} \mathrm{~atm}, 3 \times 10^{-2} \mathrm{~atm}, 4 \times 10^{-2} \mathrm{~atm}$ dan $5 \times 10^{-2} \mathrm{~atm}$ masingmasing dengan waktu deposisi selama 60 menit dan pada variaasi waktu 30 menit, 60 menit, 90 menit, 120 menit dan 150 menit masing-masing dengan tekanan $3 \times 10^{-2}$ atm sedang untuk parameter lainnya dibuat konstan dengan tegangan kerja $2.2 \mathrm{kV}$, arus kerja $20 \mathrm{~mA}$ dan jarak antar anoda dengan katoda $2.5 \mathrm{~cm}$. Hal ini dilakukan untuk memperoleh data parameter proses tekanan dan waktu sputtering yang optimum, sehingga dihasilkan lapisan tipis $\mathrm{ZnO}: \mathrm{Al}$ yang homogen di atas permukaan substrat alumina.

Untuk mengetahui keberhasilan pembuatan lapisan tipis dari parameter proses yaitu tekanan dan waktu deposisi, maka dilakukan pengukuran resistansi untuk menentukan suhu operasi sensor, sensitivitas terhadap gas : $\mathrm{C}_{2} \mathrm{H}_{5} \mathrm{OH}, \mathrm{NH}_{3}$ dan $\mathrm{SO}_{2}$.

\section{HASIL DAN PEMBAHASAN}

Dari hasil penelitian deposisi lapisan tipis $\mathrm{ZnO}$ :Al pada permukaan substrat alumina dengan variasi waktu deposisi sputtering : 30 menit, 60 menit, 90 menit, 120 menit dan 150 menit. Serta variasi tekanan gas argon : $1 \times$ $10^{-2} \mathrm{~atm}, 2 \times 10^{-2} \mathrm{~atm}, 3 \times 10^{-2} \mathrm{~atm}, 4 \times 10^{-2} \mathrm{~atm}$ dan $5 \times 10^{-2} \mathrm{~atm}$. Untuk mengetahui keberhasilan pembuatan lapisan tipis ZnO:Al pada sustrat alumina, maka dilakukan karakterisasi yang meliputi : pengukuran resistansi, penentuan suhu operasi dan sensitivitas sensor terhadap gas uji.

\section{Pengaruh Waktu Deposisi terhadap Resistansi Lapisan Tipis ZnO:Al}

Hasil pengukuran resistansi lapisan tipis ZnO:Al terhadap variasi waktu deposisi masing-masing : 30 menit, 60 menit, 90 menit, 120 menit dan 150 menit pada tekanan $4 \times 10^{-2}$ atm. ditunjukkan pada Gambar 2 .

Pada Gambar 2 menunjukkan bahwa nilai resistansi cenderung menurun dengan bertambahnya waktu deposisi. Hal ini karena dengan waktu yang semakin lama maka jumlah atom-atom $\mathrm{ZnO}$ :Al yang terdeposisi ke 
permukaan substrat akan semakin banyak sehingga atom-atom pada permukaan substrat akan semakin rapat dan homogen. Hal ini menyebabkan jarak antar atom pada permukaan akan semakin pendek sehingga pembawa muatan (elektron) yang melewati daerah tersebut akan semakin mudah. Kondisi ini berpengaruh terhadap kenaikkan konduktivitas bahan sensor (sifat kelistrikan menjadi lebih konduktif atau resistansi bahan semakin menurun).

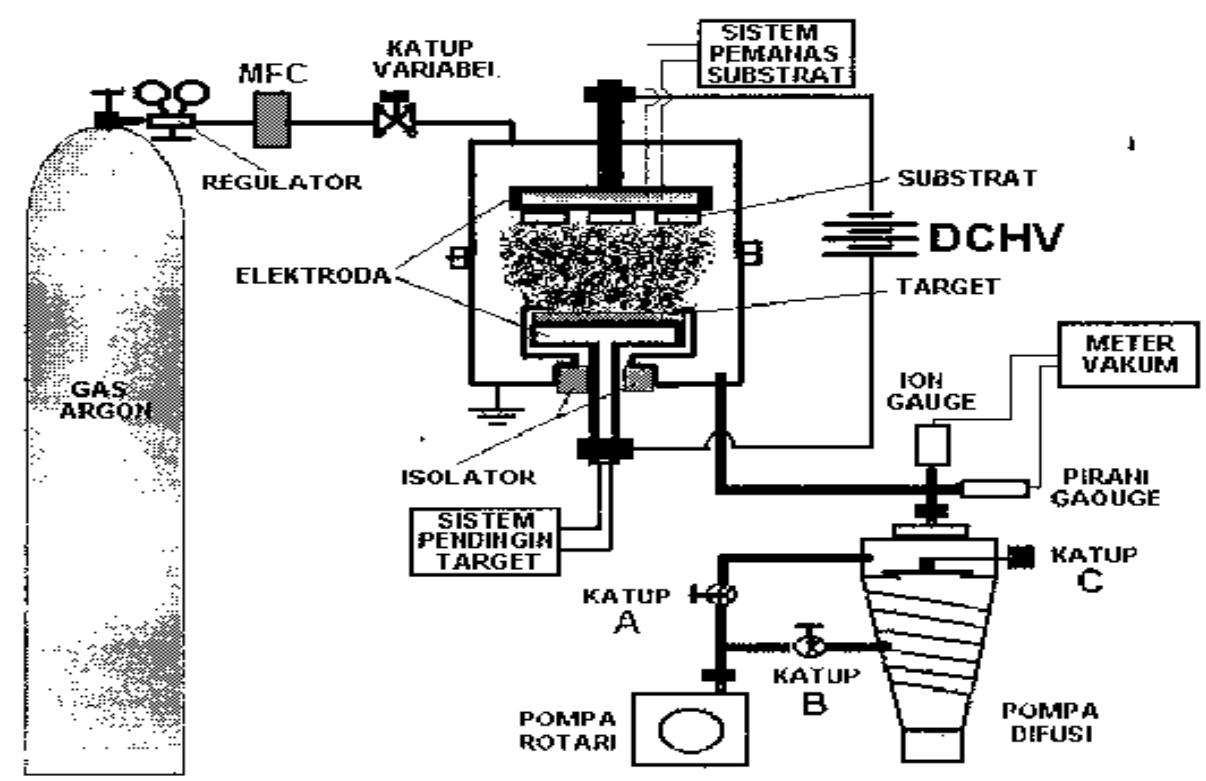

Gambar 1. Sistem DC sputtering.

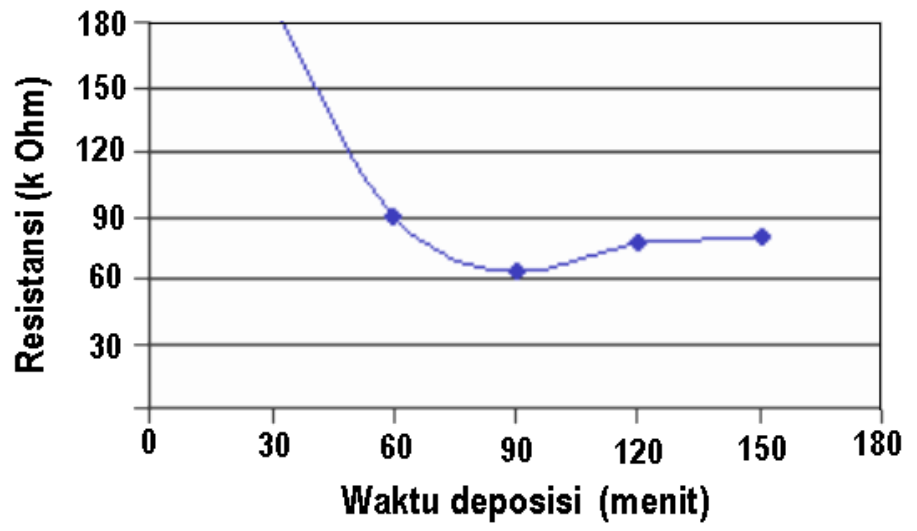

Gambar 2. Resistansi lapisan tipis ZnO:Al terhadap waktu deposisi.

Tetapi bila waktu deposisi terus dinaikkan nilai resistansi bukannya semakin turun tetapi justru mengalami kenaikan, hal ini karena akibat energi sputtering yang diberikan pada proses pembuatan lapisan adalah konstan $(2,2 \mathrm{kV} / 20 \mathrm{~mA})$ dengan demikian jarak jangkauan atom-atom yang tersputter masuk ke dalam permukaan substrat akan sama sehingga akan terjadi penumpukan atom-atom ZnO:Al pada permukaan substrat sehingga membentuk semacam isolator yang berakibat terhadap penurunan konduktivitas bahan sensor. Dari hasil pengukuran resistansi terhadap perubahan waktu deposisi diperoleh nilai resistansi terendah sebesar $64 \mathrm{k} \Omega$

Pengaruh Tekanan Operasi terhadap Resistansi Lapisan Tipis.

Hasil pengukuran resistansi lapisan tipis ZnO:Al terhadap perubahan tekanan ditunjukkan pada Gambar 3. 
Gambar 3 menunjukkan nilai resistansi lapisan tipis ZnO:Al dari variasi tekanan operasi sputtering masingmasing : $1 \times 10^{-2} \mathrm{~atm}, 2 \times 10^{-2} \mathrm{~atm}, 3 \times 10^{-2} \mathrm{~atm}, 4 \times 10^{-2} \mathrm{~atm}$ dan $5 \times 10^{-2} \mathrm{~atm}$. Tekanan gas yang semakin tinggi akan meningkatkan jumlah atom gas argon dalam tabung plasma, karena tekanan gas sebanding dengan jumlah atonnya.

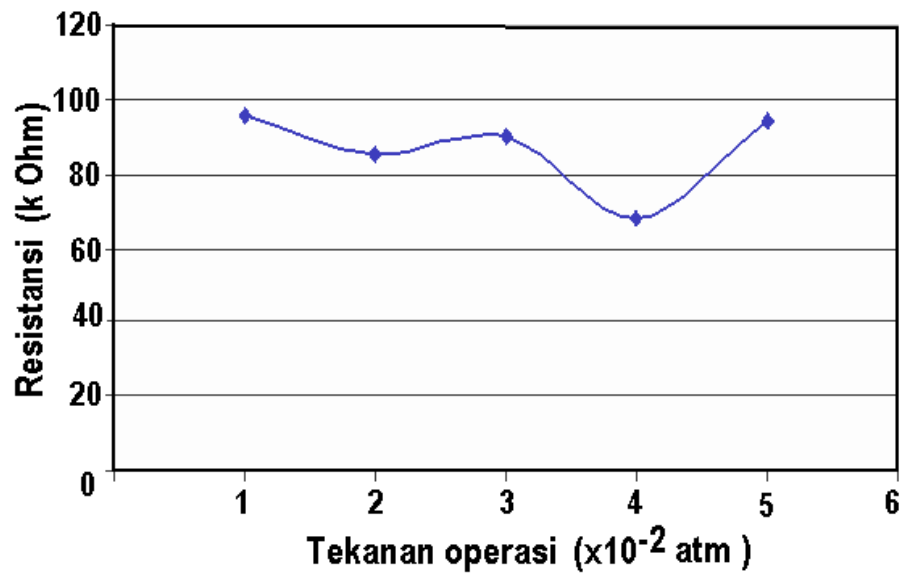

Gambar 3. Hubungan antara resistansi lapisan tipis ZnO:Al terhadap tekanan operasi.

Bila tekanan gas semakin rendah, maka jum-lah ion argon dalam tabung plasma yang berfungsi sebagai gas sputter juga masih sedikit. Akibatnya jumlah atom-atom target $\mathrm{ZnO}: \mathrm{Al}$ yang tersputter ke permukaan substrat alumina masih kecil sehingga tingkat kerapatan dan homogenitas atom pada permukaan yang berfungsi sebagai sensor masih rendah. Oleh karena tingkat kerapatan dan homogenitas atom pada permukaan masih rendah maka jarak antar atom masih ada celah/gap sehingga elektron sebagai pembawa muatan akan sulit melewati pada daerah tersebut, ini berpengaruh terhadap konduktivitas bahan sensor masih rendah atau nilai resistansinya masih tinggi (dalam orde $\mathrm{M} \Omega$ hingga ratusan $\mathrm{k} \Omega$ ).

Apabila tekanan gas argon semakin tinggi, maka jumlah ion argon akan semakin banyak, akibatnya jumlah atom-atom yang timbulkan juga bertambah banyak sehingga dapat meningkatkan kerapatan dan homogenitas atom-atom pada permukaan, ini berpengaruh pada kenaikan konduktivitas bahan sensor sehingga terjadi penurunan nilai resistansi (dalam orde $\mathrm{k} \Omega$ hingga $\Omega$ ). Sedangkan bila tekanan gas argon terus dinaikkan akibatnya akan terjadi penumpukan atom-atom target pada permukaan bahan sensor sebagaimana terjadi pada penambahan waktu deposisi yang berlebihan sehingga bukannya penurunan nilai resistansi tetapi justru terjadi sebaliknya nilai resistansi mengalami kenaikan kembali, hal ini terbukti pada tekanan yang lebih besar $\left(5 \times 10^{-2}\right.$ atm) menghasilkan nilai resistansinya $97 \mathrm{k} \Omega$ dan pada tekanan $4 \times 10^{-2} \mathrm{~atm}$ nilai resistansinya $68,1 \mathrm{k} \Omega$ sebagaimana ditunjukkan pada Gambar 3. Dengan demikian baik waktu deposisi maupun tekanan operasi sputtering mempunyai kondisi tertentu atau kondisi optimum, ini dicapai pada kondisi tekanan $4 \times 10^{-2}$ atm dengan nilai resisistansi sebesar $68,1 \mathrm{k} \Omega$. Kemudian dari hasil pengukuran nilai resistansi variasi waktu deposisi dan tekanan operasi sputtering dipilih yang mempunyai nilai resistansi terendah dalam hal ini pada kondisi waktu deposisi selama 90 menit dengan tekanan $4 \times 10^{-2}$ atm diperoleh nilai resistansi $64 \mathrm{k} \Omega$. Selanjutnya sampel tersebut dilakukan uji untuk menentukan suhu operasi sensor.

\section{Penentuan Suhu Operasi Sensor ZnO:Al}

Penentuan suhu operasi sensor sangat diperlukan karena pada rentang tertentu lapisan tipis ZnO:Al dapat berfungsi sebagai sensor gas. Dalam penentuan suhu operasi sensor dilakukan dengan cara dipanaskan bahan sensor gas secara bertahap mulai suhu kamar hingga suhu tertentu untuk memperoleh nilai resistansi yang stabil. Hasil pengamatan suhu operasi sensor ditunjukkan pada Gambar 4.

Pada Gambar 4 menunjukkan bahwa semakin suhu dinaikkan maka nilai resistansi cenderung menurun, hal ini terjadi akibat adanya migrasi elektron dari pita valensi menuju ke pita konduksi (menjadi elektron bebas). Pada Gambar 4 terlihat bahwa mulai suhu $150^{\circ} \mathrm{C}$ penurunan resistansi sudah rendah dan menuju kondisi stabil 
pada rentang $175{ }^{\circ} \mathrm{C}-200{ }^{\circ} \mathrm{C}$. Pada kondisi suhu $175^{\circ} \mathrm{C}-200{ }^{\circ} \mathrm{C}$ bahan ZnO:Al dapat berfungsi sebagai sensor gas karena perubahan resistansi sensor gas tidak dipengaruhi oleh panas tetapi disebabkan adanya proses serapan gas yang mengenai permukaan bahan sensor.

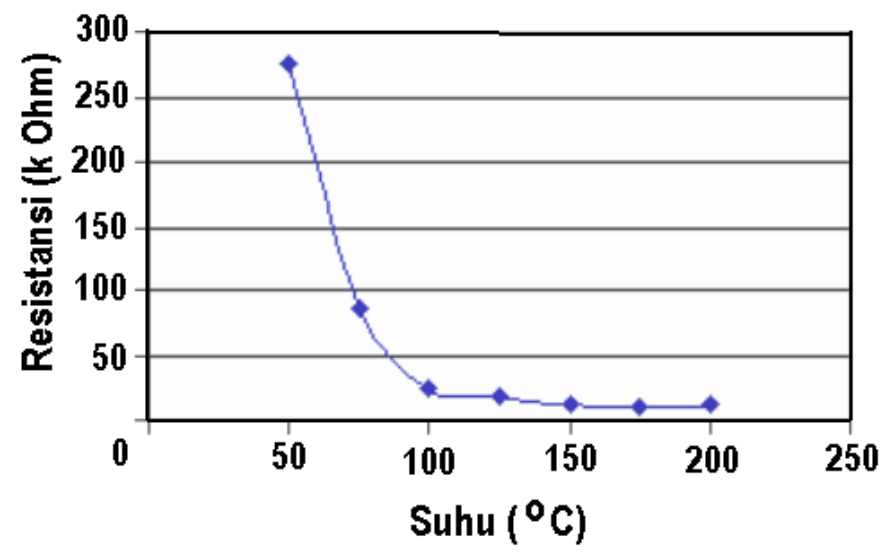

Gambar 4. Hubungan resistansi lapisan tipis ZnO:Al terhadap suhu.

Pada beberapa sensor, nilai resistansi kembali menunjukkan gejala kenaikan pada suhu di atas $325{ }^{\circ} \mathrm{C}$. Gasov dan Rumyantseva (1999) mengatakan bahwa hal tersebut dapat terjadi karena pada suhu di atas suhu operasi sensor, oksigen yang terabsorbsi akan menarik elektron dari bagian dalam butir yang mengakibatkan pertambahan ketebalan lapisan deplesi yang terlalu besar sehingga butir akan berada pada daerah bebas/kosong elektron yang menyebabkan peningkatan resistivitas. Pada penelitian ini suhu operasi sensor diperoleh $200{ }^{\circ} \mathrm{C}$. Suhu ini menjadi acuan suhu operasi sensor gas untuk pengujian sensitivitas.

\section{Pengujian Sensitivitas Sensor Gas ZnO:Al}

Pengujian sensitivitas sensor ZnO:Al dilakukan menggunalan 3 jenis gas uji yakni : ethanol $\left(\mathrm{C}_{2} \mathrm{H}_{5} \mathrm{OH}\right)$, amoniak $\left(\mathrm{NH}_{3}\right)$ dan sulfur oksida $\left(\mathrm{SO}_{2}\right)$. Sensitivitas diperoleh dengan menentukan nilai resistansi sensor sebelum dan sesudah dikenai gas kemudian dihitung menggunakan perasamaan (7) maka sensitivitas sensor gas dapat diketahui. Hasil perhitungan sensitivitas sensor gas dari bahan $\mathrm{ZnO}$ :Al terhadap gas uji ethanol $\left(\mathrm{C}_{2} \mathrm{H}_{5} \mathrm{OH}\right)$, amoniak $\left(\mathrm{NH}_{3}\right)$ dan sulfur oksida $\left(\mathrm{SO}_{2}\right)$ ditunjukkan pada Gambar 5 .

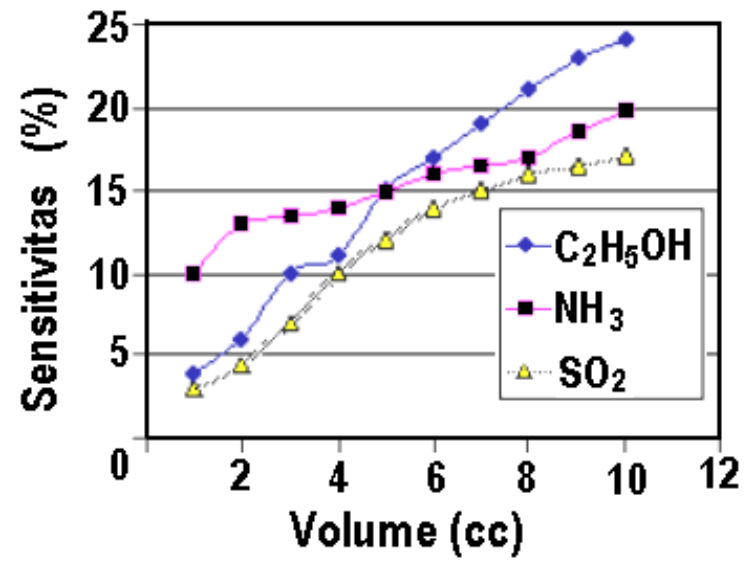

Gambar 5. Sensitivitas sensor terhadap gas $\mathrm{C}_{2} \mathrm{H}_{5} \mathrm{OH}, \mathrm{NH}_{3}$ dan $\mathrm{SO}_{2}$.

Dari Gambar 5 menunjukkan bahwa bahwa mulai volume $1 \mathrm{ml}$ atau 14,15 konsentrasi/volume sensor telah dapat merespon gas tetapi belum stabil. Tetapi setelah volume dinaikan hingga $10 \mathrm{ml}$ atau 141,54 konsentrasi/volume, maka sensitivitas sensor gas meningkat masing-masing : $24 \%\left(\mathrm{C}_{2} \mathrm{H}_{5} \mathrm{OH}\right), 19,77 \%\left(\mathrm{NH}_{3}\right)$ dan 
$17,53 \%\left(\mathrm{SO}_{2}\right)$. Ini menunjukkan bahwa sensor gas dari bahan $\mathrm{ZnO}$ :Al memiliki sensitivitas cukup baik terhadap kehadiran ketiga gas tersebut, karena sensor dapat merespon dengan stabil mulai volume $6 \mathrm{ml}$ atau konsentrasi 84,92 konsentrasi/volume. Kondisi dicapai oleh sensor yang dibuat dengan parameter proses sputtering sebagai berikut : Waktu deposisi 90 menit, tekanan $4 \times 40^{-2}$ atm, suhu sputtering $250^{\circ} \mathrm{C}$, tegangan $2,2 \mathrm{kV}$, arus $20 \mathrm{~mA}$ dan suhu operasi sensor $200{ }^{\circ} \mathrm{C}$.

\section{KESIMPULAN}

berikut :

Dari hasil penelitian deposisi lapisan tipis ZnO:Al sebagai bahan sensor, maka dapat disimpulkan sebagai

1. Hasil proses deposisi lapisan tipis $\mathrm{ZnO}: \mathrm{Al}$ sebagai bahan sensor gas diperoleh nilai resistansi terendah 64 $\mathrm{k} \Omega$, kondisi ini dicapai pada waktu deposisi 90 menit, tekanan $4 \times 10^{-2} \mathrm{~atm}$, tegangan $2,2 \mathrm{kV}$, arus $20 \mathrm{~mA}$ dan suhu substrat $250^{\circ} \mathrm{C}$.

2. Pada penentuan suhu operasi sensor gas pada rentang suhu 175 sampai dengan $200{ }^{\circ} \mathrm{C}$ diperoleh nilai resistansi yang stabil sehingga suhu $200^{\circ} \mathrm{C}$ ditetapkan sebagai suhu operasi sensor.

3. Sensor gas dari bahan lapisan tipis ZnO:Al pada 141,54 konsentrasi/volum mempunyai sensitivitas terhadap gas uji masing-masing : $24 \%\left(\mathrm{C}_{2} \mathrm{H}_{5} \mathrm{OH}\right), 19,77 \%\left(\mathrm{NH}_{3}\right)$ dan $17,53 \%\left(\mathrm{SO}_{2}\right)$.

\section{UCAPAN TERIMA KASIH}

Dengan telah selesainya penelitian ini kami mengucapkan banyak terima kasih kepada Bapak : J. Karmadi dan seluruh staf kelompok Aplikasi Akselerator atas segala bantuan yang telah diberikan.

\section{DAFTAR PUSTAKA}

1. COSANDEY, F., SKANDON, G., SINGHAL, A, Material and Pocessing Issues in Nanostructured Semiconductor Gas Sensors, The Minerals, Metals and Materials Society, 2000.

2. MARDARE, D., RUSU, G.L., Structural and Electrical Properties of $\mathrm{TiO}_{2}$ RF Sputerred Thin Films, Materials Science and Engineering, B75, 68-71, 2000.

3. WASA, K., HAYAKAWA, S., Handbook of Sputter Deposition Technology and Application, Noyes Publication, New Jersey, 1992.

4. GAS'KOV, A.M., RUMYANTSEVA, M.N., Materials for Solid-State Gas Sensors, Inorganic Materials, Vol.36, No.3, 293-301, 2000.

5. OHRING, M., The Material Science of Thin Films, Academic Press Inc., New York, 1992. 